\title{
The Value of Toys: 6-8 -year-old children's toy preferences and the functional analysis of popular toys
}

\author{
Pekka Mertala*, Hannele Karikoski, Liisa Tähtinen \& Vesa-Matti Sarenius \\ Faculty of Education, University of Oulu, Oulu, Finland.
}

\begin{abstract}
The aim of this study was to explore the kinds of toy preferred by 6-8-year-old children, asking: how, and on what basis, do children rationalize their preferences for particular toys? Data was collected by interviewing children in their homes. Children chose 8 toys from a tailored catalog and explained why they wanted those particular items. Toys were analyzed with the aid of a framework designed to test their functional manipulation potential. The children's reasoning was analyzed by means of inductive content analysis. Two kinds of values were found: 1.) those which reside in the toy itself; and 2.) those which children give to toys. Sub-categories relating to material, social, and personal values were identified from the given values. The present paper deepens knowledge of the value of toys not only as playthings but also as cultural artifacts which children use as one form of their voice.
\end{abstract}

Keywords: toy, preference, play, affordance

\section{Introduction: a Piagetian approach to playing with toys}

This study is a part of broader research project 'Play in different contexts', which is being conducted in collaboration with a Finnish toy importer and marketing company. ${ }^{1}$ In this article, our focus is on the views of 6-8-year-old children concerning the value of toys. The present paper compares the views expressed by a test-group of children regarding the particular features of toys they consider important during the process of toy selection with our own expectations (based on the available research literature) concerning the impact of particular affordances and built-in features of toys in the formation of children's preferences.

As our focus in this study is on playing with toys, we will approach play as a form of object manipulation. Here we are following a developmentalistic approach which finds its roots in Jean Piaget who identified a strong relation between play and development which could be divided into certain stages. Piaget addresses cognitive development as an internal process and separates out the types of play that occur before and after children learn to combine imagination with action. The earliest forms of play, where no use of imagination occurs, are what Piaget calls 'practice play'. When the imagination has developed enough, surrounding objects no longer determine the content of play as children are capable of manipulating their meanings through symbolic object transformation (a process which Piaget named 'symbolic play'). A third stage, according to Piaget is 'rule play', in which rules can be either given (as in games), or created spontaneously during play. (Blake \& Pope, 2008; Matusov \& Hayes, 2000, 216; Nicolopoulou, 1993; Piaget, 1962, 97-98, 143-146.) However it should be noted that Piaget's theory regarding the development of play does not hold a monopolizing position in the field of play-theory, and that the broader idea of developmentalism has

\footnotetext{
* Corresponding author. Email: pekka-oskari.mertala@oulu.fi

${ }^{1}$ This work was supported by the LEIKKAAMO-project under Grant [24301143].
} 
been criticized by deconstructionalist psychologists and proponents of the New Sociology of Childhood. For example Nicolopoulou (1993) criticizes Piaget for neglecting the social features of play and James, Jenks and Prout (1998, 17-18) state that there has been a growing dissatisfaction towards the universal, predetermined and sequenced nature of children's development (see also Lourenco \& Machado, 1996).

However, Piaget's theory has been the base for many of the former toy classifications (Almqvist 1994). The latest approach following this path is Kudrowitz's and Wallace's (2010) 'play pyramid', where toys are labeled by means of Piagetian framework and a play scale based on classic play theories from Caillois, Huizinga, and Parten. Classifications have also been based on the level of toys' resemblance to real life objects and agents (Wright 2003) and their ability to promote social play (Ivory \& McCollum 1999). In several cases, categorizations are used as qualitative and descriptive umbrella terms even though they have been derived from limited and potentially homogenous samples. For example in Hughes's (1999) classification puzzles, drawing instruments and books are labeled as gender neutral toys. The problem with these umbrella terms is that here are thousands and thousands of different puzzles, pens and books and although some of them surely can be labeled neutral there are roughly an equal number that cannot. To avoid this problem and an overwhelming number of different umbrella classes (see Nelson 2005) we will next present the idea of the functional manipulation potential of toys: a taxonomic model which is based on their built-in purposes.

\section{The functional manipulation potential of toys}

In our model, Piaget's ideas on the relation of cognitive development to forms of object manipulation are re-conceptualized in terms of functional thinking / symbolic thinking and functional manipulation / symbolic manipulation. By 'functional thinking which leads to functional manipulation' we mean forms of play in which no symbolic thinking is needed. Examples of such play-types can be throwing or kicking a ball, sliding, flying a kite, playing a board game etc. By 'symbolic thinking that leads to functional manipulation' we mean forms of play in which symbolic thinking is needed to actualize the functional manipulation potential of a certain toy, and which describes the ways in which the user is intended to play with it. For example, acting out a caregiverchild-role-play with a doll requires that the player transforms the doll into a baby by using his/her ability for symbolic thinking. By 'symbolic thinking that leads to symbolic manipulation', we mean cases in which the result of manipulation cannot be returned to the functional manipulation potential of a toy. In the case of the baby doll, the play-type can be tracked back its functional play affordances as it resembles a real baby and thereby creates the opportunity for socio-dramatic role-play. But if children use hobbyhorses as rifles, the form of manipulation cannot be seen to result from a functional manipulation potential of the toy even though the shape of actual toy and its symbolic transformation have some physical resemblance. The model of functional manipulation potential is presented in table 1. Its affordances and elements including their sub-features and our model's roots in former studies are discussed in more depth in the following section. 
Table 1. The functional manipulation potential of toys

\begin{tabular}{|l|l|l|}
\hline \multicolumn{3}{|c|}{ Functional manipulation potential } \\
\hline \multicolumn{3}{|c|}{ Functional play value } \\
\hline Attractive affordance & Pragmatic affordance & Adaptive affordance \\
\hline $\begin{array}{l}\text { Representational element } \\
\text { realistic; fantasy-oriented }\end{array}$ & \multicolumn{3}{|c|}{$\begin{array}{l}\text { Gender element } \\
\text { female; male }\end{array}$} \\
\hline $\begin{array}{l}\text { Sensory element } \\
\text { visual; tactile; auditive; olfactory }\end{array}$ & $\begin{array}{l}\text { Productive element } \\
\text { constructive; aesthetic; given; open ended }\end{array}$ \\
\hline & $\begin{array}{l}\text { Performative element } \\
\text { performative; transitive }\end{array}$ & \\
\hline & Normative element & \\
\hline & Technological element & $\begin{array}{l}\text { Social element } \\
\text { competitive; collaborative }\end{array}$ \\
\hline $\begin{array}{l}\text { Motoric element } \\
\text { cross; fine }\end{array}$ & $\begin{array}{l}\text { Academic element } \\
\text { mathematic; linguistic; } \\
\text { memory; conceptualization }\end{array}$ & \\
\hline
\end{tabular}

In the present context, functional refers to intentional built-in features that provide pragmatic, attractive or adaptive affordances (e.g. Kudrowitz \& Wallace, 2010; Papanek, 1971) and thus encourage particular forms of play (Ruckenstein, 2010). Manipulation connotes the understanding of play as different forms of object manipulation (e.g. Piaget, 1962). Potential accepts that the actualization of functions depends on the subjective cognitive and motoric skills of the players as well as their spatial or structural configuration (e.g. Kline, 1999; Piaget, 1962; Sutton-Smith, 1986; Van Leeuwen, 2005). For example, the performative potential of a toy dog does not actualize for a small baby who hasn't yet developed the ability to engage in symbolic thinking. Potential also tails off as children develop. As soon as children learn to master a clock, an academic potential is lost from games that practice such mastery (such as 'Tick Tock'-game in this study), although other elements (for example the social function of a multiplayer game) still remain.

To be labelled as a toy, an artifact must intentionally produce affordances for playing (Kudrowitz $\&$ Wallace, 2010). It must, in other words, have a functional play value which can be dominant or latent. A toy car by itself has all that is needed for playing with it, but a garage needs a car for functional use. Therefore pragmatic affordances can be seen as the core-affordances. Attractive affordances are the sum of built-in features that invite children to pick out a certain toy from the broader toy-pool. Representationality is always an attractive affordance and, naturally, its attractive purpose is clearest in cases where it provides no other affordances (for example a ball that has a 
picture of a princess or a fairy on it). Likewise, different sensory features increase the realistic representationality of a toy (a dog that barks / doll that cries) or may provide other attractive supplements (pens that have a scent). By adaptive affordances, we mean instances in which toys can act in at least two different roles. Examples of toys with adaptive affordances include construction blocks, as these furnish the opportunity to create constructions which may then be used in sociodramatic role play (Van Leeuwen, 2005, 50-51).

Representational elements can be labeled as realistic or fantasy-oriented. The realistic label is given to toys which replicate real life archetypes (Hughes, 1999; Kline, 1999; Nelson, 2005). This feature is dominant when the whole toy is a replica of the target and moderate when a representational element, usually a picture, is added to an otherwise non-representational toy. With respect to Genderoriented elements, we follow views represented in previous studies (e.g. Blakemore \& Centers, 2005; Eisenberg, Murray \& Hite, 1982; Miller, 1987) and use familiar cultural constructions as a means of defining what is masculine, feminine and neutral. For example a police car (along with all of its baggage of cultural connotations relating to action and aggression) is labeled as strongly masculine whereas a baby doll that relates to care-giving is labeled as strongly feminine. These are what Papanek (1971) identifies as the 'universal associations' that derive from the human desire to give items other values besides those which have already been designated. Sensory elements are those features of toys that produce a sensory stimulus. Features created in this way may be auditory, visual, tactile and olfactory and their effectiveness varies on a scale from moderate to dominant. For example a pram rattle that moves and shakes has both pragmatic and attractive affordances for a small baby as the rattling sound and colorful moving figures encourage children to reach their arms or legs towards it (Van Leeuwen 2005, 79-86). Productive elements can be divided between constructions and aesthetic productions. Constructions can be further subdivided into given and open-ended productions. A jigsaw puzzle has a given constructive value, generic building blocks are open-ended, while themed Lego sets are both as, although they direct children to build certain types of construction, they are not restricted to this remit. Jigsaw puzzles also lack the adaptive affordance that construction blocks have. The difference between aesthetic productions which elicit sensory responses and 'plain' sensory response is determined by the extent to which the sensory response relates to other features. Pushing a button that makes a baby doll cry does not come out as an aesthetic auditory product but as a realistic representational feature. Kline (1999) describes performatives as representational hints of 'what the toy can do' and 'what type of role children should make the action figure play'. Our understanding of performative element of toys is somewhat broader than Kline's as we expand the idea of performativeness to include also role play clothes, toy guns etc. Thus, in our model, performative elements can actualize in two different features. The expression 'performative feature' refers to an action where children act or embody a role (Kalliala, 1999, 153). For example a baby doll has a performative value as, by playing with it, children embody themselves as the caregivers. Likewise, 'Transitive features' refer to forms of play where children act out a role by a toy. Thus types of toys that represent something but are not meant to be used in socio-dramatic role play do not contain transitive values as elements in their performative feature (see the case of 'the digging set' in table 2). According to Bretherton (1984), children can act in two different roles while playing with figures. They can be both narrators who recount what the characters are doing and vicarious actors who act and speak on behalf of the lifeless toys. In a broader sense the whole model of functional manipulation potential is a normative term itself, as functionality tends to limit the possibilities for manipulation (Norman, 1988, 9-11). The presence of normative elements implies that functional manipulation is 
possible only by following rules. Rules are here understood not only as protocols followed when playing games but also as 'rules in form' which, for example, have a dominant feature in jigsaw puzzles and a moderate feature in types of Lego ${ }^{\mathrm{TM}}$ which offer both a model and instructions for building a construction at the same time as they also encourage personal outcomes. Technological elements are dominant in toys that can no longer be functionally manipulated if the technological features are damaged and moderate in toys that can still fill their functional purpose even when technological features don't work (Allen, 2004, 179). With respect to social elements, Ivory and McCollum (1999) suggest that toys can be divided in two categories: those which promote social play and those which do not. Here it is somewhat problematic that our expectations regarding the social use of toys and their actual use do not always match, and social use seems to be highly context related. For example according to Sutton-Smith (1986, 37-38), toys, in the family context are meant to encourage solitary play but children with siblings or peers in the neighborhood will naturally use toys for social play. Borenstein (1996, 213-218) argues that toys increase the amount of social interaction as they constitute a form of language that children can share and use. Bergen, Hutchinson, Nolan and Weber (2010) have studied the social affordances of toys for infant-parent play and found that social integration can be supported by certain features. However for present purposes, 'social features' are understood as connoting a need for at least two players to use a toy functionally, while 'social interaction' can be either co-operative or competitive. The motoric element of toys is divided in two categories: fine and gross. Their features are dominant or moderate. To be dominant, the motoric feature needs to be the main function of the toy (as in the cases of hula-hoop or a jumping rope). Moderate motoric value is determined by comparing motoric tasks to other functional potentials provided by the toy. We have chosen to use term academic (rather than 'pedagogic') element to emphasize the ambiguous relation between 'learning and play' and 'learning and toys', as both learning and play are concepts which are difficult to define unambiguously (see Almqvist, 1994). Following the logic of functional manipulation, the academic element is limited to possible learning experiences children can glean from intentionally inserted features. By emphasizing this, we are not claiming that children would not learn from playing with other kinds of toys (or, indeed, no toys at all); rather, we are merely underlining the point that some toys have been designed with the purpose of teaching children about numbers or letters, for example (see Hartmann \& Brougère, 2004, 47).

\section{Children's Toy Preferences}

Contemporary toys in most Western contexts are predominantly understood as objects that have been manufactured and purchased for children to play with (Gougoulis, 2003, 10; Nelson, 2005). Besides their value as playthings, commercial toys are said to have various cultural values. Sutton-Smith (1986) has observed that toys have meanings in relation to bond and obligation, solitariness, consolation, technology, education, agency and market. Through cultural-semiotic analysis, researchers have found that toys may enshrine views of gender and ethnic-based roles (Kress \& Van Leeuwen, 2006; Wright, 2003), or allude to gender, race and ethnic stereotypes (Best, 1998; Kline, 1999; Martens, Southerton \& Scott, 2006; Sherman \& Zurbriggen, 2014). To have toys and to know what toys one should have are forms of children's cultural knowledge that may be transformed into social capital among peers (Kalliala, 1999; Puroila \& Estola, 2012).

Children's toy preferences have been subject to a moderate amount of study. The background

variable examined is usually the gender of informants (Cherney \& Dempsey, 2010). Children's levels 
of reading (Billie, 1984), the social values of surrounding society (Nelson, 2005), the degree and frequency of their exposure to toy commercials (Bujitzen \& Walkenburg, 2000; Pine \& Nash, 2002), and brand awareness (O'Cass \& Clarke, 2002) have also been the main subject or co-subject in past studies, though - with the exception of Billie's (1984) study - gender related analysis has played a marked role in all of the works mentioned. According to Nelson (2005) there are is a body of literature indicating that girls and boys tend to prefer and choose toys that are traditionally feminine or masculine. Wright (2003) states that Barbie-doll is more than a toy as it mimics the female form, stands for a woman and functions as a tool for self-imagining. Kline (1999) notes that, similarly, the action figures designed for boys offer them hyper-masculine models of behavior. It seems that the eagerness to focus on the gender-issue is built around the question of how playing with stereotypical toys affects children's views of themselves and views regarding their possible agency as members of their gender (Sherman \& Zurbiggen, 2014).

Two alternative data-gathering methods are usually followed in toy preference studies. The first is to offer a set of actual toys or pictures of toys for children to choose from (Cherney \& Dempsey, 2010; Eisenberg et al., 1982; Escudero, Robbins \& Johnson, 2013). A second method has been to collect and analyze children's 'Dear Santa' -letters (Bujizen \& Walkenburg, 2000; Downs, 1983; Halkoaho, Laakso, Laaksonen \& Lahti, 2009; Pine \& Nash, 2002; O'Cass \& Clarke, 2002). A distinction can also be made between the studies where children name toys from a pool they know well (for example toys that are their own or toys at their day care center, see Hartmann \& Brougère 2004) and studies where children have no or only a little 'hands on' experience of the toys (dear Santa -studies). Children tend to prefer toys related to their own gender (Cherney, 2006Cherney \& Dempsey, 2010; Hartmann \& Brougère 2004; cf. Downs, 1983). According to Blakemore \& Centers (2005), boys over 4 years old tend to regard toys that they consider to be feminine as 'hot potatoes': something to avoid. Children's reasoning about toys and their preferences for particular toys is a less well-studied subject. In an examination of 3-5 -year old children's reasoning concerning toys and gender relations (Cherney \& Dempsey, 2010), the color of the toy was the key factor for labeling, though only a few children were able to reason their preferences. A study by Eisenberg et al. (1982) revealed that 3-4 -year-old children use a noticeable amount of gender related reasoning when choosing toys for others but concentrate more on what they can do with the toy when picking toys for themselves. In two studies egocentric views were the primary forms of reasoning, as in: 'what I like, children of my sex will also like and children of the other sex will not like' (Martin, Eisenbud \& Rose 1995; see also Cherney, 2006). We believe that by examining toys as physical items with certain functions, we are able to analyze in more depth and clarity the tapestry of toy-based values, culture-based values, social-based values and subjective values which children see in toys. Through this approach, we are also trying to avoid the problem of over-generalization found in some earlier studies. For example in Miller's (1987) classification, balls were said to relate to aggression and thus to be masculine. A closer examination, however, reveals that the sample contained two balls, both of which were replicas of balls that are used in ball games that include a great deal of contact (Almqvist, 1994; Blakemore \& Centers, 2005). It can be argued that a similar study done with different balls would come up with different results.

\section{Method}

Rather than aiming for a large scale study, we were keen to find fewer - but informant rich - cases (Patton, 1990, 169). Thus a snowball method was used to reach suitable informants. At the first stage, 
parents of a local preschool group were informed about the study. At the second stage they passed the word to their friends and so on. In the end, a cohort of thirteen (13) children from six to eight years old participated in the study, comprising seven girls and six boys from ten families. The study was conducted in urban southern Finland and the socio-economic backgrounds of the families can be described as middle-class or upper middle-class (Bureau of Statistics, 2012). A few days before the interview, a tailored catalog of 45 age-appropriate toys was given to children along with the instruction to choose eight toys that they would like to have (see appendix 1). The variety of items in the catalog was diverse. It contained toys that could be labeled as masculine (Spy gear, cars), feminine (princess costumes, fairy wings), trendy (Angry birds, Bratz) traditional (board games, Rubik's cube, puzzles), or technology-enhanced (iPawn, Chatimals). All children were interviewed twice and every child was interviewed individually. The data used in this study was collected from the first interview. All the interviews were done by the same researcher. According to Adler \& Adler $(2002,528)$ the topic of the interview must determine where the interviews are done. Thus interviews were done in children's own homes as we thought that a familiar environment and the presence of their own toys would support children's narrations. Roos and Rutanen (2015) note that unpredictability is always present when interviewing children: they can be extremely talkative or give one-word answers and the gathered data may lead researchers to change their research questions. There were, indeed, notable variations in the length of the children's narratives. The shortest interview lasted 14 minutes and the longest 61 minutes. It should be noted that toy preferences were only one of the themes discussed, others being for example children's concepts of what play is and what playing means to them. All the interviews followed the same logic. First children were asked a few warm up questions (for example how their day had been) and then interviewer started to guide the discussion towards play and toys. Toys were discussed one toy at a time by using the catalog as a mediating tool. According to Lipponen, Rajala, Hilppö \& Paananen (2015) looking at, pointing to, and commenting on the same representation helps different parties to understand each other. The children were asked during the interview to explain their preferences to the interviewer and to discuss their ranking criteria. No fixed questions, other than asking children why they want the particular toy, was used. All the interviews were recorded and transcripted.

Our main research tasks were to study what type of toys children chose and how they reasoned out their preferences. We were interested in the question as to whether children based their preferences on actual features of toys or whether their preferences were bound up with other factors (media, peers etc.). From a Piagetian perspective, children who participated in this study were either at pre-operational or formal operational stages. According to Piaget's play theory, the types of play most common for children would then be role play and rule play. Our first hypothesis was based on this view as we assumed that children would choose toys that promote role play (i.e. those which have dominant values associated with performative and representational elements) and those which promote rule play (i.e. have their dominant values associated with normative elements). Based on previous studies, we also assumed that boys and girls would choose different toys and that boys would be stricter with regard to choosing toys that they label as gender-appropriate.

An analysis of the toys' functional manipulation potentials and their relation to hypotheses based on Piaget's theory concerning the development of play was conducted by means of deductive content analysis by using the framework model of functional manipulation potential. Analysis of children's reasoning was done by means of inductive content analysis (Miles \& Huberman, 1994, 1012). Limitations of the present study reside in the narrow and homogenous sample of informants, and 
also the use of a catalog which restricted children's choice options (especially as the catalog was built around products of a single importing company).

\section{Results}

A total number of 25 toys was chosen. The digging set was the most popular toy as 11 out of 13 children wanted it. Table 2. presents the functional analysis of the five most popular toys from boys and girls. The number is based on the 'dear Santa' -studies (Bujizen \& Walkenburg, 2000; Downs, 1983; Halkoaho et al. 2009; Pine \& Nash, 2002; O'Cass \& Clarke, 2002), where the number of wishes varied between 3,5 and 7,2 with the mean settling at 4,85 toys.

Table 2. Functional analysis of the five most popular toys ${ }^{2}$

\begin{tabular}{|c|c|}
\hline Boys & Girls \\
\hline $\begin{array}{l}\text { Digging set } \\
\text { Representational (PATR); Productive (CG); Normative (X) }\end{array}$ & $\begin{array}{l}\text { Speed pawn -dog } \\
\text { Representational (PATR), Performative (T) }\end{array}$ \\
\hline $\begin{array}{c}\text { Defiant track \& car } \\
\text { Representational (PATR); Gender (M) } \\
\text { Productive (CG); Performative (t); Technology (X); } \\
\text { Normative (x) }\end{array}$ & $\begin{array}{l}\text { Bratz winter world } \\
\text { Representational (PATRf); Gender (F); Performative (T) }\end{array}$ \\
\hline $\begin{array}{c}\text { Angry Birds Star Wars } \\
\text { Representational (PAtFr); Gender (m); Performative (T) }\end{array}$ & $\begin{array}{c}\text { Bratzilla } \\
\text { Representational (PATFr); Gender (F); Performative (T) }\end{array}$ \\
\hline $\begin{array}{c}\text { Spy gear } \\
\text { Representational: (PATRf); Gender (M); Performative (P); } \\
\text { Technology (x) }\end{array}$ & $\begin{array}{l}\text { Lalaloopsy } \\
\text { Representational (PATRf); Gender (F); Performative (P) }\end{array}$ \\
\hline $\begin{array}{c}\text { Nikko car } \\
\text { Representational (PAtR); Gender (M); Performative (t); } \\
\text { Technology (X) }\end{array}$ & $\begin{array}{l}\text { Digging set } \\
\text { Representational (PATR); Productive (CG); Normative (X) }\end{array}$ \\
\hline
\end{tabular}

Based on Piaget's theory of stages of play, our hypothesis was that children would choose toys that contain representational, performative and normative elements. As shown in table 2, representational elements with pragmatic affordances were notably high in both boys' and girls' wishes as were performative elements with performative and transitive features. A normative element appeared in the most popular toys as a 'rule in form'. For example the dinosaurs in the digging set needed to be put together by following instructions precisely. As there was only one possible solution for constructing the dinosaur, the normative value was labeled high. With a 'Defiant' car track, children can construct a variety of different types of race tracks - with the prerequisite that it be in a somewhat circular shape - and all of these representations are valid in terms of functional manipulation: which is not the case with the digging set. Combining this finding with the twelve wishes for games, reveals an overall interest in toys that had a normative element, even though no game was interesting enough to gain more than four wishes. Yet it should be noted that two most popular games were both either

\footnotetext{
${ }^{2}$ Capital letters stand for dominant value and lower cases for moderate value; $\mathbf{P}$ is pragmatic affordance; $\mathbf{A T}$ is attractive affordance; in representational element $\mathrm{R}$ is realistic value and $\mathrm{F}$ is fantasy-oriented value. In gender-oriented element $\mathrm{F}$ is feminine value and $\mathrm{M}$ is masculine value. In productive value $\mathrm{C}$ is construction and $\mathrm{G}$ is given. In performative element $\mathrm{P}$ is performative value and $\mathrm{T}$ is transitive value. In normative and technological elements their existence is marked with an $\mathrm{X}$
} 
dominant (iPawn) or moderate (Rubik's Race) in their technological elements. The distinction between performative and transitive features within the relevant performative element is based on the different characteristics of the toys. For example, Lalaloopsy is a full-size doll and is thus equivalent to classic baby dolls that are used in socio-dramatic play where children act as caregivers. Bratz-dolls are smaller and more mature looking than Lalaloopsys and thus afford forms of manipulation where children are expected to present their role via the figure rather than situating themselves and the figure as actors, as they would with full-size dolls. The interest of Boys towards the 'Defiant' racing car and that of the Girls towards Bratz-dolls are similar to Hartmann's and Bourgue's (2004) findings indicating that in the context of contemporary western culture, there are some cross-cultural genderrelated similarities in children's toy preferences. The representational elements of Angry Bird -space figures were labeled highly fantasy-oriented, but with a moderate realistic feature. The realistic feature comes from the fact that even though the figures are caricature-like and may even be represented as Star Wars characters, they can still be labeled as birds and pigs. A similar reasoning is used with Bratzilla-figures. Basic Bratz-dolls, despite their huge eyes and lips, are representations of humans, and thus may be labeled as realistic with moderate fantasy-oriented features. Cars and dinosaurs were highly realistic representations of real life objects and actors.

\section{Four values of toys}

Researcher: So you wanted that Baby born -dog?

Girl 1 (8): Well I wanted it because I like dogs a lot and it has its own bone and drinking bottle and collar and it looks so cute! I'm going to name him Wally!

Researcher: Oh, you have already a name for him. That's really nice!

Our analysis of the children's reasoning revealed four types of values: functional play value, material value, social value and personal value. Values are more overlapping than distinct (figure 1).

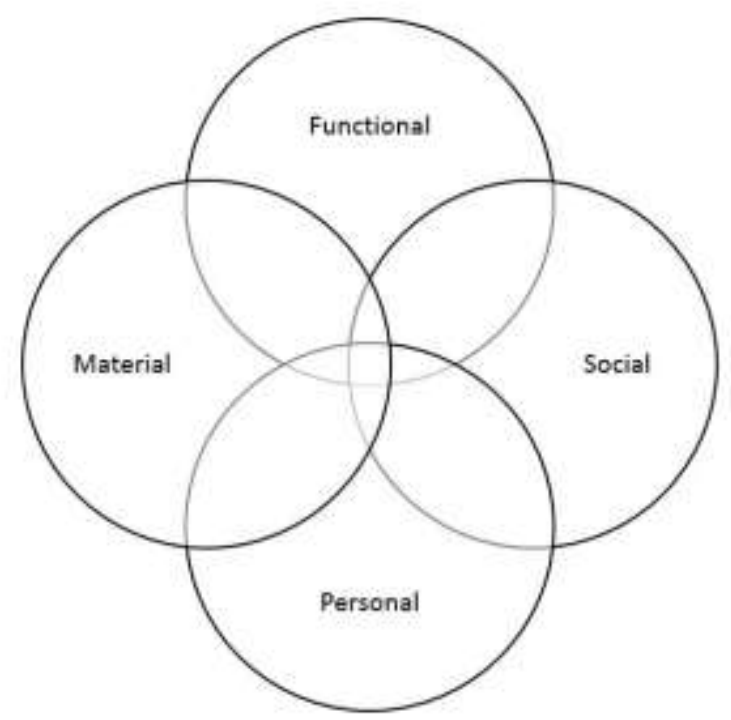

Figure 1. The four values of toys 
Getting a new toy always increases children's material resources even if children reason their needs according to other types of values. Further, as noted earlier, toys as material resources and oases of cultural knowledge may be transformed into forms of social capital that have an impact on children's social positions and their relations among their peers (Borenstein, 1996; Puroila \& Estola, 2012). For example the previous extract from an interview of an 8-year-old girl shows that her preferences are based on personal and functional values, as she already has an existing interest in dogs which complements the representational and performative elements found in the requisite toy. Naming the dog also implies that she is going to play with it.

\section{Functional value}

Girl 1: I like babies. They are fun to carry and feed and dress-up. I can nurture it like if it's a real baby.

Functional play value refers to children's reasoning based on the different functional elements of toys. Eisenberg et al. (1982) call this 'action oriented reasoning', because it is based on what can be done with the toy in question. The passage above is from an 8-year-old girl's reasoning as to why she wants a baby-doll. Her answer contains an understanding of the performative element whereby symbolic thinking is needed to actualize the functional manipulation potential. Pragmatic affordances were often mentioned as well. Another girl said that she would like to have the 'Tick tock' -game so that she could learn time, implying that she was basing her reasoning on a desire to utilize the academic element of the particular toy. Here, a boy reasons out his preferences by mentioning that engaging with the normative element behind Rubik's cube, solving the problem by following rules, fascinates him.

Researcher: Why do you want to have a Rubik's cube?

Boy 1 (8): Because it is interesting.

Researcher: Why do you find it interesting?

Boy 1: Because it must be solved by getting the colors right.

The attractive affordances activated by representational elements in toys were important to girls: terms such as 'cute, lovely, adorable' etc., often appearing in their reasoning.

\section{Material value}

Girl 2 (8): It comes with lot of accessories! It's good because I have only a few Bratzthings...

No children chose fewer than eight toys. Two boys asked for one extra toy outside the catalog. The amount is higher than in 'Dear Santa' -studies where the number of wishes varied between 3,5 and 7,2 with the mean settling at 4,85 toys. The significance of ownership was notable in cases where children reasoned that they collected certain types of toys or already had them but wanted more (Puroila \& Estola, 2012). In some of these cases children did not refer to playing with the toy at all. In these cases, toys were seen more as collectibles than things to play with. Further, the amount of 
extra material provided with the toy was important to children (One girl pointed out that she was happily surprised when she later realized that her Lalaloopsy play set contained more extras than were shown in the catalog). Girls also preferred a toy dog that came with care-giving accessories (water pot, leash etc.), over a dog that came without accessories. Here material resources overlap with functional affordances, as (according to the children) accessories make the dog more realistic (a clear case of dominant values being based on realistic representationality). According to Piaget $(1962,135-$ 138) children's role play develops in a more realistic direction as children grow older.

\section{Social value}

Researcher: So why did you want this spy gear -set?

Boy 2 (7): Well, maybe because Jonas likes to spy and he comes often to play at my place.

The social value of toys can be seen to derive from socially constructed values and the expectation of future social interaction. According to Borenstein (1996), toys are a language children share and use. Some children said that they wanted certain toys because they knew their friends liked them and having them would promote social play. Friends were also named as the source of information on the subject of which toys are desirable (see Kalliala, 1999). Socially constructed preferences played a big role in children's reasoning as, for the majority of children participating, friends were related to at least one toy preference. Two boys even asked for Skylander -figures that weren't included in catalog - as both of them had seen Skylanders when visiting a friend. Blakemore's and Centers's (2005) finding that boys consciously avoid feminine toys was notable in this study as well. Even though some boys were interested in the Star wars Angry Bird -figures, none of them chose the feminine Stella / Princess Leia -bird. One of the boys highlighted the point that he didn't like the 'pink princessbird'.

\section{Personal value}

Girl 3 (8): Well because they go shopping and I really like to go to clothes-stores.

Researcher: Was there something else that you liked about it (a Bratz Boutique figure)?

Girl 3: No. I just really like shopping.

The extract above has many similarities with the example of the girl talking about a baby doll. However, there is a one significant difference. Unlike the case of the baby doll, the girl here is not saying that she likes role play which includes shopping or that she will play in this way with her new doll. It is valuable for the girl because it represents something she finds pleasing in the real life. Overall, children reflected their personal experiences and aesthetic views on toys a lot. Four girls reported that they were interested in dogs and that they would therefore like to have a toy dog to play with. Two girls explained their liking for a Bratzilla-doll by saying that they could use its hair-do and costume as an inspiration for their Halloween-party apparels. Two girls also justified their preference for a doll with a certain hair color through its similarity to the color of their own hair. 


\section{Researcher: What about that digging set then?}

Boy 3 (6): Well because I like it a lot... and we did break ice at pre-school

Researcher: So you are a true digger then.

Boy 3: We pretended that ice was gold.

The preference here derives from earlier enjoyable experiences that the boy had associated with the digging set as the latter promised similar activities to those connected with his earlier experience (breaking ice with tools / breaking the stone around the fossil with tools). Likewise one girl, when asked why she had chosen a digging set, replied that she used to collect dinosaurs and draw dinosaurbooks when she was younger.

\section{Conclusions}

Our findings indicate that the grounds on which children base their preferences for toys are multilayered, as the four values found (functional, material, social and personal) overlap one another. Our Piagetian-based assumption, of children showing an interest in toys that had representational, performative, and normative elements was supported by our findings. Representational elements with pragmatic affordances were notably high in both boys' and girls' wishes, as were performative elements with performative and transitive features. Different types of games gained twelve nominations but no game was interesting enough to attract the attention of more than three children. However, normative elements were present in the digging set and racing car track as 'a rule in form' because it was necessary that they were put together either by way of a precise following of instructions or, at least, with some degree of freedom. In line with previous studies, gender-based differences were also notable. Some children connected the amount of accessories with the realism of toys that were replicas of real life agents. A dog with a leash and water-pot was 'more dog' than a one without. The impact of socially constructed values was notable as well. Children said that having a certain toy would promote their chances of social play as their friends were interested in those particular toys. Friends and their toys were also named as the source of knowledge with regard to the toys in which one was supposed to be interested. There were also some traces of meaningfulness with regard to functional social elements, as four children wanted multiplayer board games. At a personal level, children reflected their past experiences and current topics of interest, as well as their views of aesthetics and self-realization, in terms of toys. For example the ways in which children react to the attractive features of dolls (hair color, for instance), relate to their habitus or understanding of aesthetics.

Our findings support those of Hartmann and Brougère (2004) as we both confirmed, for example, that girls like doll-figures such as Barbie and Bratz while boys like cars. Besides that, our small-scale approach was able to reveal something new about the basis on which children form their preferences. For example, girls reasoned their preferences on many occasions by referencing material and personal values. It seems that in many cases there is an existing interest towards certain themes or phenomena which leads children to seek toys which manifest these wishes and ideas in a concrete form. This is in line with Gibson's (1979) argument that the experience of an affordance is always subjective. However, understanding the actualization of affordances as subjective interpretations does not preclude the existence of more general forms of affordance. Different types of affordances with 
regard to functional manipulation potential were important for some of the children (see the cases of the baby-doll and Rubik's Cube). It is possible that functional features are something that children just do not actively analyze as other values, such as the material, personal and social, may be the ones they are more aware of. For example, boys didn't express their keenness for racing cars and tracks through function-based reasoning. Yet, nevertheless, cars were a shared target of interest: indicating that there must be something in the toy itself which is visible and meaningful for a large group of boys (see Hartmann \& Brougère, 2004): even if these features are not discussed in an explicit manner by children. According to Piaget (1962), the older the children get, the more realistic their role play becomes. Thus it is possible that the dominant realistic representational value of the racing cars (and the dinosaur-skeletons in the digging sets) could have been a significant factor even when it is not explicitly articulated.

One interesting group comprised children who reported that they would like to own certain toys but did not necessarily intend to play with them. In these cases, toys were seen more as collectibles than things to play with. Some scholars have noted that the contemporary toy-industry primarily relates to already existing stories that have proved their popularity in other forms, for example as movies or TV-series (see Kline, 1999). Angry Birds Star Wars -figures in this study are a descriptive example of multiple layers of media-references in toys. Both Angry Birds and Star Wars have been a huge success in several fields of cultural production and here they are united in a one toy. This raises questions as to what owning a lot of contemporary popular and highly media-related toys means for children? One approach to this question could be to study the ownership of collectibles as forms of cultural and social capital (Bourdieu, 1986). However these questions are left for future studies to explore. Besides the questions already examined, it would be interesting as well as important to study how both children's reasoning and the functional manipulation potential of toys correlate with the actual play activities children experience as they use them.

\section{Notes on contributors}

Pekka Mertala, Hannele Karikoski and Vesa-Matti Sarenius work in Department of Education in University of Oulu, Mertala as a project researcher and Karikoski and Sarenius as tenured lecturers. Liisa Tähtinen is a primary school teacher. This study is a part of broader research project `Play in different contexts', which is being carried out in collaboration with a Finnish toy importer and marketing company AMO Oy.

\section{Acknowledgements}

We wish to thank Professor Anthony Johnson for proofreading our article and the anonymous reviewers of The International Journal of Play for valuable comments.

\section{References}

Adler, P.A. \& Adler, P. 2002. The reluctant respondent. In: J.A. Holstein \& J. F. Gubrium (Eds.). Handbook of interview research: Context and method. Thousand Oaks, CA: Sage, 515-535. 
Allen, M. (2004). Tangible interfaces in smart toys. In J. Goldstein, D. Buckingham \& G. Brougère (Eds.), Toys, games, and media. Mahwah, New Jersey. Lawrence Erlbaum Associates, 179194.

Almqvist, B. (1994). Approaching the culture of Swedish child care: A literature survey and a toy inventory. Stockholm: Nordstedts Tryckeri AB.

Bergen, D., Hutchinson, K., Nolan, J.T. \& Weber, D. (2009). Effects of infant-parent play with a technology-enhanced toy: affordance-related actions and communicative interactions." Journal of Research in Childhood Education 24(1), 1-17. doi:10.1080/02568540903439342

Best, J. (1998). Too much fun: Toys as social problems and the interpretation of culture. Symbolic Interaction, 21(2), 197-212. doi:10.1525/si.1998.21.2.197.

Blake, B. \& Pope, T. (2008). Developmental psychology: Incorporating Piaget's and Vygotsky's theories in classrooms. Journal of Cross-Disciplinary Perspectives in Education, 1, 59-67.

Blakemore, J.E.O. \& Centers, R.E. (2005). Characteristics of boys' and girls' toys. Sex Roles. 53(910), 619-633. doi:10.1007/s11199-005-7729-0

Borenstein, L. (1996). The development of friendship in childhood: a clinical conversation. Child and Adolescent Social Work Journal, 13(3), 213-224. doi:10.1007/BF01875788

Bourdieu, P. 1986. The forms of capital. In J. G. Richardson (Ed.) Handbook of theory and research for the sociology of education. New York: Greenwood, 241-258.

Bretherton, I. (1984). Representing the social world in symbolic play: Reality and fantasy. In I. Bretherton (Ed.), Symbolic play: The development of social understanding. New York: Academic Press, 3-41

Bujizen, M. \& Walkenburg, P.M. (2000). The impact of television advertising to children's Christmas wishes. Journal of Broadcasting and Electronic media, 44. 456-470. doi: 10.1207/s15506878jobem4403_7

Bureau of Statistics (2014). Tulonjaon kokonaistilasto 2013, tuloskehitys alueittain [Statistics on income distribution in 2013] [pdf]. Retrieved from http://www.stat.fi/til/tjkt/2013/01/tikt_2013_01_2014-12-18_fi.pdf

Cherney, I. (2006). Gender-linked differences in the toys, television shows, computer games, and outdoor activities of 5- to 13-year-old children. Sex Roles, 54(9-10), 717-726. doi:10.1007/s11199-006-9037-8

Cherney, I. \& Dempsey, J. (2010). Young children's classification, stereotyping and play behaviour for gender neutral and ambiguous toys. Educational Psychology: An International Journal of Experimental Educational Psychology, 30(6), 651-669. doi:10.1080/01443410.2010.498416

Cougoulis, C. (2003). The material culture of children's play: Space, toys and the commoditization of childhood in a Greek community. Doctoral dissertation, University College, London.

Downs, C.A. (1983). Letters to Santa Claus: Elementary school-age children's sex typed toy preferences in a natural setting, Sex Roles, 9(2), 159-163. doi:10.1007/BF00289620

Eisenberg, N; Murray, E. \& Hite, T. (1982). Children's reasoning regarding sex-typed toy choices. Child Development, 53(1), 81-86. doi:10.1111/1467-8624.ep8587561

Escudero, P., Robbins, R., \& Johnson, S. (2013). Sex-related preferences for real and doll faces versus real and toy objects in young infants and adults, Journal of Experimental Child Psychology, 116(2), 367-379. doi:10.1016/j.jecp.2013.07.001

Gibson, J. J. (1979). The ecological approach to visual perception. Hillsdale, New Jersey: Lawrence Erlbaum Associates, Inc. 
Halkoaho, J., Laakso, M., Laaksonen, P. \& Lahti, J. (2009). Joulun taikaa vai tahdottua tavaraa? Lasten lahjatoiveet joulun hengen osoittajina. [The magic of christmas or desired goods? Childrens christmas wishes as indicators of christmas spirirt]. Kulutustustkimus.Nyt, 1. 73-86.

Hartmann, W. \& Brougère, G. (2004). Toy culture in preschool education and children's toy preferences. In: J.Goldstein, D. Buckingham and G. Brougère (Eds.) Toys, Games and Media, N.Jersey and London: Lawrence Erlbaum. 37-54.

Hughes, F. P. (1999). Children, play and development. Boston: Allyn and Bacon.

Ivory, J. J. \& McCollum, J. A. (1999). Effects of social and isolate toys on social play in an inclusive setting. Journal of special education, 32(4), 238-243.

doi:10.1177/002246699903200404

James, A., Jenks, C. \& Prout, A. (1998). Theorizing childhood. Cambridge, UK: Polity Press.

Kalliala, M. (1999). Enkeliprinsessa ja itsari liukumäessä. Leikkikulttuuri ja yhteiskunnan muutos. [The angel-princess and suicide in silde. Play-culture and changes in society], Helsinki: Gaudeamus Oy, Yliopistokustannus University Press Finland Ltd.

Kline, S. (1999, June). Toys as media: The role of toy design, promotional TV and mother's reinforcement in the young males (3-6) acquisition of pro-social play scripts for Rescue Hero action toys. Paper presented at ITRA Conference, Halmstadt, Sweden. [pdf]. Retrieved from http://www.sfu.ca/media-lab/risk/docs/media-lab/toys_as_media_kline.pdf.

Kress, G. \& Van Leeuwen, T. (2006). Reading images: The grammar of visual design. (2nd ed.) London \& New York: Routledge

Kudrowitz, B. \& Wallace, D. (2010). The play pyramid: A play classification and ideation tool for toy design. Int. Journal of Arts and Technology, 3(1), 36-56. doi:10.1504/IJART.2010.030492

Lambert, E.B. \& Clyde, M. (2003). Putting Vygotsky to the test. In D. Lytle (Ed.), Play and educational theory and practice. Play and culture studies 5. Westport CT: Praeger. 59-98.

Lipponen, L., Rajala, A., Hilppö, J., \& Paananen, M. (2015). Exploring the foundations of visual methods used in research with children. European Early Childhood Education Research Journal, (ahead-of-print), 1-11. doi:10.1080/1350293X.2015.1062663

Lourenço, O., \& Machado, A. (1996). In defense of Piaget's theory: A reply to 10 common criticisms. Psychological review, 103(1), 143-164.

Martens, L; Southerton, D. \& Scott, S. (2004). Bringing children (and parents) into the sociology of consumption: Towards a theoretical and empirical agenda. Journal of Consumer Culture 4(2), 155-182. doi: $10.1177 / 1469540504043680$

Martin, C. L., Eisenbud, L. and Rose, H. (1995), Children's Gender-Based Reasoning about Toys. Child Development, 66(5), 1453-1471. doi: 10.1111/j.1467-8624.1995.tb00945.x

Matusov, E. \& Hayes, R. (2000). Sociocultural critique of Piaget and Vygotsky. New Ideas in Psychology, 18, 215-239. doi:10.1016/S0732-118X(00)00009-X

Miles, M.B. \& Huberman, A.M. (1994). Qualitative Data Analysis (2nd ed.) London: Sage.

Miller, C.L. (1987). Qualitative differences among gender-stereotyped toys: Implications for cognitive and social development in girls and boys. Sex Roles, 16(9-10), 473-487. doi:10.1007/BF00292482

Nelson, A. (2005). Children's toy collections in Sweden - A less gender-typed country? Sex Roles, 52(1-2), 93-102. doi:10.1007/s11199-005-1196-5

Nicolopoulou, A. (1993). Play, cognitive development and the social world: Piaget, Vygotsky, and beyond. Human Development, 36(1), 1-23. doi:10.1159/000277285 
Norman, D. (1988). The design of everyday things. New York: Basic Books.

Ortega, R. (2003). Play, activity, and thought: Reflections on Piaget's and Vygotsky's theories. In Lytle, D. (Ed.). Play and educational theory and practice. Play and culture studies 5. Westport CT: Praeger. 99-115.

O'Cass, A. \& Clarke, P. (2002). Dear Santa, do you have my brand? A study of the brand requests, awareness and request styles at Christmas time. Journal of Consumer Behavior, 2(1), 37-53. doi:10.1002/cb.88

Papanek, V. (1971). Design for the real world: Human ecology and social change, New York, Pantheon Books.

Patton, M. 1990. Qualitative evaluation and research methods. Beverly Hills, CA: Sage. 169-186.

Piaget, J. (1962). Play, dreams and imitation in childhood. Abingdon, Oxon: Routledge.

Pine, K.J. \& Nash, A. (2002). Dear Santa: The effects of television advertising on young children. International Journal of Behavioral Development. 26(6), 529-539. doi:10.1080/01650250143000481

Puroila, A-M. \& Estola, E. (2012). Lapsen hyvä elämä? Päiväkotiarjen pienten kertomusten äärellä. [A good life of a child? The small stories of daycare-children]. Journal of Early Childhood Education Research, 1(1), 22-43.

Roos, P. \& Rutanen, N. (2014). Metodologisia haasteita ja kysymyksiä lasten tutkimushaastattelussa [Methodological challenges in reserach interviews with children]. Journal of Early Childhood Education Research, 3(2), 27-47.

Ruckenstein, M. (2010). Toying with the world: Children, virtual pets and the value of mobility. Childhood 17(4), 500-513. doi: 10.1177/0907568209352812

Sherman, A. \& Zurbriggen, E.L. (2014). "Boys Can Be Anything": Effect of Barbie Play on Girls' Career Cognitions. Sex Roles 70(5-6), 195-208. doi: 10.1007/s11199-014-0347-y

Sutton-Smith, B. (1986). Toys as culture. New York, London: Gardner Press.

Thomas, B. (1984). Early toy preferences of four-year-old readers and nonreaders. Child Development, 55[2], 424-430. doi:10.1111/1467-8624.ep7304539

Van Leeuwen, T. (2005). Introducing social semiotics. Abingdon, Oxon: Routledge.

Wright, L. (2003). The wonder of Barbie: Popular culture and the making of female identity. Essays in Philosophy, 4(1). [pdf] Retrieved from:

http://commons.pacificu.edu/cgi/viewcontent.cgi?article=1075\&context=eip 
Appendix. An example page of the catalog

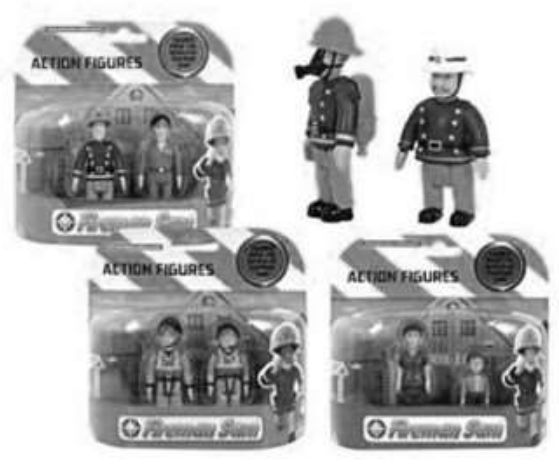

03366 PALOMIES SAMI

PIKKUFIGUURI

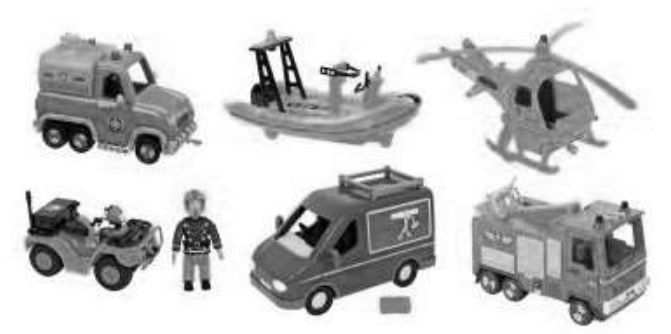

03367 PALOMIES SAMI AJONEUVO

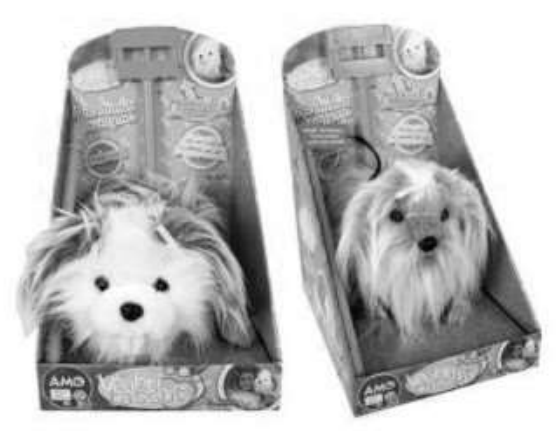

7800 VAUHTITASSUT KOIRA

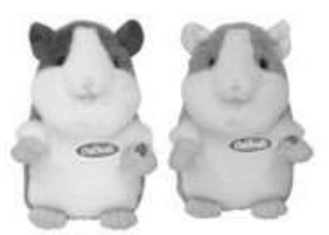

80092

CHATIMALS

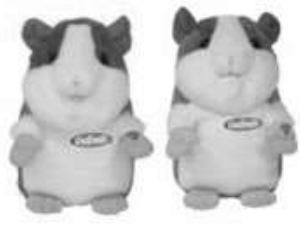

